\title{
CONSCIÊNCIA FONOLÓGICA E VOCABULÁRIO EXPRESSIVO EM CRIANÇAS COM AQUISIÇÃO TÍPICA DA LINGUAGEM E COM DESVIO FONOLÓGICO
}

\author{
Phonological awareness and expressive vocabulary in children \\ with normal language acquisition and with phonological disorders
}

\author{
Tassiana Isabel Kaminski ${ }^{(1)}$, Helena Bolli Mota ${ }^{(2)}$, Carla Aparecida Cielo ${ }^{(3)}$
}

\section{RESUMO}

Objetivo: comparar o desempenho em vocabulário expressivo e consciência fonológica entre crianças com desvio fonológico e com aquisição típica da linguagem e analisar a influência da idade neste desempenho. Método: os participantes foram divididos em grupos de controle (GC) e estudo (GE) e apresentavam idades entre cinco e sete anos. Foram aplicados os testes de vocabulário expressivo e consciência fonológica, e foi realizada análise estatística dos dados. Resultados: as crianças do GE, de uma maneira geral, atingiram um desempenho inferior aos participantes do GC nas tarefas analisadas. As crianças do GE de cinco e do GE de sete anos apresentaram alguns resultados significativamente inferiores ao GC; porém não houve diferenças entre os grupos de seis anos. Ao comparar o desempenho das crianças com os valores de referência, as crianças de cinco anos, de ambos os grupos, apresentaram dificuldades nas mesmas tarefas, de vocabulário expressivo e consciência fonológica, com variações de complexidade. Os sujeitos de seis e sete anos mostraram dificuldades apenas em vocabulário expressivo. Conclusão: as crianças com desvio fonológico apresentaram um desempenho inferior em algumas habilidades de vocabulário e consciência fonológica quando comparadas às crianças com desenvolvimento típico. Pode-se concluir ainda que existe influência da idade no desempenho destas habilidades para ambos os grupos, pois, com o aumento da idade, os participantes apresentaram dificuldades apenas em vocabulário e não mais em consciência fonológica.

DESCRITORES: Testes de Linguagem; Semântica; Vocabulário; Linguagem Infantil; Desenvolvimento da Linguagem

\section{INTRODUÇÃO}

O desenvolvimento fonológico é um processo gradual de aquisição do sistema de fones

(1) Fonoaudióloga clínica; Mestre pelo Curso de Pós - graduação em Distúrbios da Comunicação Humana da Universidade Federal de Santa Maria, Santa Maria, RS, Brasil.

(2) Fonoaudióloga; Professora Adjunta do Curso de Fonoaudiologia e do Mestrado em Distúrbios da Comunicação Humana da Universidade Federal de Santa Maria, Santa Maria, RS, Brasil; Doutora em Lingüística Aplicada pela Pontifícia Universidade Católica do Rio Grande do Sul.

(3) Fonoaudióloga; Professora Adjunta do Curso de Fonoaudiologia e do Mestrado em Distúrbios da Comunicação Humana da Universidade Federal de Santa Maria, Santa Maria, RS, Brasil; Doutora em Lingüística Aplicada pela Pontifícia Universidade Católica do Rio Grande do Sul.

Conflito de interesses: inexistente contrastivos e das estruturas silábicas que termina quando a criança atinge o sistema padrão/adulto. Espera-se que crianças entre quatro a seis anos de idade apresentem seu sistema fonológico adquirido sem alterações. Porém, esta aquisição pode diferir do esperado e algumas crianças apresentarem dificuldade na organização mental dos sons da língua, no estabelecimento do sistema fonológico alvo, bem como na adequação do input recebido, caracterizando o desvio fonológico ${ }^{1}$. Por ser uma dificuldade de organização do sistema de sons, os casos de desvio fonológico, em geral, não apresentam problemas em nível articulatório, e sim no desenvolvimento fonológico, estando ausente uma etiologia orgânica aparente ${ }^{2}$. 
A consciência fonológica é a habilidade em analisar a fala em seus componentes fonológicos ${ }^{3}$. Estudos referem que estas habilidades podem sofrer influência da idade ${ }^{4} \mathrm{e}$ da alfabetização ${ }^{3-8}$. Em relação à variável sexo, pesquisas em crianças com desenvolvimento típico de linguagem ${ }^{9,10} \mathrm{e} \mathrm{em}$ crianças com desvio fonológico ${ }^{11,12}$ não encontraram diferenças estatisticamente significativas no desempenho em consciência fonológica entre meninos e meninas

Para sujeitos com desenvolvimento típico da linguagem, existe uma sequência de aquisição dos diferentes tipos de habilidades em consciência fonológica, iniciando com a habilidade em consciência de palavras, seguida pela de rimas, depois de sílabas e, por último, de fonemas ${ }^{3}$.

Segundo autores ${ }^{13,14}$, crianças com desvio fonológico podem desenvolver alterações em consciência fonológica e apresentar desempenhos inferiores ao de crianças com aquisição típica da linguagem. Estes desempenhos poderiam melhorar com um programa terapêutico ${ }^{15,16}$ que tornasse estas crianças mais atentas em relação aos sons da fala e capazes de perceber a importância da presença dos traços alterados na sua fala. Embora possam existir vários graus de gravidade de desvios fonológicos, pesquisas ${ }^{1,17,18}$ que classificaram os sujeitos de forma quantitativa não encontraram diferença estatisticamente significativa entre o grau de gravidade do desvio e o desempenho no escore total de uma prova de consciência fonológica. Ou seja, a performance em consciência fonológica não sofreu interferência da gravidade do desvio.

Quanto ao desenvolvimento semântico, em crianças com desenvolvimento típico da linguagem, o balbucio aparece por volta de seis a nove meses ${ }^{19} \mathrm{e}$ as primeiras palavras surgem em torno de dez a 15 meses de idade ${ }^{19,20}$. Há uma pequena variação de meses entre as pesquisas, mas, em geral, uma explosão na aquisição do vocabulário ocorre entre 22 e 36 meses de idade ${ }^{21}$. Este aprendizado envolve palavras relacionadas aos nomes de coisas ou pessoas e aquelas ligadas a relacionamentos sociais. O uso de verbos é mais tardio ${ }^{21}$. Entre os fatores que podem influenciar o aprendizado do vocabulário estão o ambiente humano-familiar em que a criança está inserida ${ }^{21}$, o aumento da idade das crianças ${ }^{22,23}$ e a escolaridade materna ${ }^{20}$, ou a escolaridade das pessoas envolvidas no ambiente da criança ${ }^{24}$.

Sobre a relação entre desvios fonológicos e alterações lexicais, a interferência do desvio fonológico na aquisição lexical pode influenciar a produção de palavras homônimas. Se uma criança tem poucos fonemas à disposição e tenta produzir grande número de palavras diferentes, ela simplesmente não consegue. Isso pode ser causado pela ausência de sons suficientes para pronunciar estas palavras, produzindo as formas homônimas e dificultando a compreensão de seu discurso ${ }^{19}$. O grau de compreensão das palavras também pode influenciar as características fonéticas da produção, pois uma maior exigência semântica (ou dificuldade para compreender o sentido do que será dito) poderia levar a criança a cometer mais erros na produção ${ }^{2}$.

Os resultados de um estudo ${ }^{25}$ sugerem uma relação entre o campo fonológico (a consciência fonológica e a precisão de fala) e o léxico. Assim, no estudo supracitado, déficits no vocabulário seriam indicativos de déficits em consciência fonológica.

Procurando investigar melhor a relação entre os elementos da linguagem, em especial entre fonologia e semântica, esta pesquisa visa estudar a relação entre consciência fonológica e vocabulário expressivo, e de que forma estas variáveis são influenciadas pelo desvio fonológico. Portanto, o objetivo desta pesquisa foi comparar o desempenho de crianças com aquisição típica de linguagem com o de crianças com desvio fonológico em testes de vocabulário expressivo e consciência fonológica, verificando-se também a influência da idade.

\section{MÉTODO}

Esta pesquisa se configura como um estudo de campo, não-experimental, exploratório, transversal e quantitativo.

Os dados foram coletados no período de outubro de 2007 a dezembro de 2008.

Foram analisados os comportamentos das crianças com idades entre cinco anos a sete anos, de ambos os sexos. Os participantes frequentavam o ambiente escolar, fazendo parte de turmas de educação infantil e de primeira série (alfabetização) do ensino fundamental.

Os participantes foram divididos em dois grupos: o grupo controle (GC), composto por crianças com aquisição típica da linguagem, e o grupo estudo, (GE) composto por crianças com desvio fonológico.

A coleta de dados foi realizada em um serviço público de atendimento fonoaudiológico vinculado a uma instituição de ensino superior e em duas escolas públicas e uma escola filantrópica de ensino fundamental. Optou-se realizar as coletas nestes estabelecimentos para obter um número maior de participantes.

Os procedimentos de seleção da amostra e coleta de dados foram realizados por mestrandos e acadêmicos bolsistas de iniciação científica dos $7^{\circ}$ e $8^{\circ}$ semestres da instituição de ensino superior vinculada a presente pesquisa. 
No serviço público de atendimento fonoaudiológico, a seleção dos participantes ocorreu por meio de triagens no setor responsável pelas alterações de fala, com a intenção de coletar dados de indivíduos com desvio fonológico. Os pais/responsáveis foram contatados e convidados a participar através da assinatura do Termo de Consentimento Livre e Esclarecido (TCLE). Nesse termo constavam informações sobre os objetivos da pesquisa, a justificativa, os procedimentos a serem adotados, riscos, benefícios, sigilo dos dados coletados, garantia de esclarecimento e liberdade de recusar a participar em qualquer momento. A assinatura desse documento, de livre vontade, é uma condição para a participação da criança na pesquisa, sendo possível desistir quando achar conveniente. Além da assinatura do TCLE, a criança deveria assentir sua participação na pesquisa. Os participantes selecionados neste local fizeram parte do GE.

Nas escolas, foi entregue, por intermédio dos professores, o TCLE para os pais de todas as crianças que apresentavam a idade adequada para participar da pesquisa. Os professores indicaram o horário mais adequado para que fossem realizadas as avaliações sem prejudicar a participação da criança nas atividades desenvolvidas em sala de aula. Os participantes selecionados nas escolas compuseram tanto o GE como o GC.

Todos os participantes autorizados através do TCLE passaram por uma triagem fonoaudiológica, composta por avaliações do sistema estomatognático, dos sistemas fonológico e fonético, de linguagem e triagem auditiva.

Foram considerados como critérios de inclusão na amostra do GE: autorização dos pais e/ou responsáveis através do TCLE; a criança assentir a participação; ter idade entre cinco e sete anos; apresentar desvio fonológico. Para realizar o diagnóstico de desvio fonológico, utilizou-se como fundamentação teórica o livro Avaliação Fonológica da Criança (AFC) ${ }^{2}$.

Como critérios de exclusão para o GE, consideraram-se: apresentar alterações psicológicas (inferidas pela interação com a criança observando-se os aspectos comportamentais da mesma), cognitivas e neurológicas evidentes à observação; apresentar resultados alterados na triagem fonoaudiológica quanto ao sistema estomatognático, fonético, compreensão e/ou expressão da linguagem, e triagem auditiva; ter realizado ou realizar tratamento fonoaudiológico.

Os critérios de inclusão para participar do GC foram considerados os mesmos acima citados, porém, mediante a ausência de desvio fonológico. Para esse grupo, consideraram-se os mesmos critérios de exclusão do GE.
As crianças que não passaram por um ou mais critérios de avaliação foram excluídas da amostra e encaminhadas para os procedimentos necessários, como consulta com médico otorrinolaringologista, avaliação odontológica, ou terapia fonoaudiológica, por exemplo. Assim, os participantes que não estavam dentro dos critérios de inclusão, a partir da avaliação, foram excluídos.

Dessa forma, após a seleção, o GE foi composto por 24 crianças (15 meninos e nove meninas) e o GC por 50 crianças (18 meninos e 32 meninas). Cada grupo foi dividido em três subgrupos, conforme as idades dos participantes: o GE foi formado por dez crianças de cinco anos (sete meninos e três meninas), dez crianças de seis anos (cinco meninos e cinco meninas) e quatro crianças de sete anos (três meninos e uma menina); o GC, por 12 crianças de cinco anos (três meninos e nove meninas), 27 crianças de seis anos (dez meninos e 17 meninas) e 11 crianças de sete anos (cinco meninos e seis meninas).

Para iniciar o processo de coleta de dados, os participantes selecionados foram submetidos à avaliação do vocabulário expressivo e à avaliação da consciência fonológica.

Para a avaliação do vocabulário, foi utilizada a prova de verificação do vocabulário do teste ABFW ${ }^{26}$. Esse teste avalia nove campos conceituais: vestuário, animais, alimentos, meios de transporte, móveis e utensílios domésticos, profissões, locais, formas e cores, brinquedos e instrumentos musicais. Foram apresentadas individualmente 118 figuras para a criança e ela deveria nomeálas. Suas respostas foram anotadas no protocolo do teste. $O$ teste analisa três tipos de respostas, as designações por vocábulos usuais, as não designações e os processos de substituições. Se a criança nomear a palavra corretamente, considera-se uma designação por vocábulo usual; se ela não nomear ou referir que não sabe, considera-se como uma não designação; e se ela substituir a palavra esperada por outra, considera-se como um processo de substituição. Para esta pesquisa, foram consideradas apenas as designações por vocábulos usuais das crianças do grupo, dentro de cada campo conceitual.

Nesta pesquisa, foi estabelecida uma nota de zero a 100 em cada campo conceitual, para cada participante, para possibilitar a análise dos dados e comparação entre os dois testes utilizados. Esta nota foi uma porcentagem calculada da seguinte forma: número de designações por vocábulos usuais utilizadas, dividido pelo número de itens a serem designados em cada campo conceitual e multiplicados por 100 . 
Os resultados obtidos em cada grupo foram comparados com um percentual de respostas (valor de referência) que deve ser considerado como adequado para cada faixa etária estudada. Este percentual esperado encontra-se presente no próprio teste ${ }^{26}$ e seus valores diferem de acordo com a faixa etária, ou seja, há um percentual adequado para a idade de quatro anos, valores diferentes para cinco anos e outros para seis anos. No teste não há um valor de referência para a idade de sete anos, portanto consideraram-se os valores da idade de seis anos como o mínimo a ser atingido, e as crianças de sete anos deveriam ter uma pontuação maior do que a esperada para seis anos de idade.

As habilidades em consciência fonológica foram avaliadas por meio do protocolo de avaliação das habilidades de consciência fonológica (PTCF) ${ }^{4,27}$. Foram aplicadas apenas as tarefas propostas às faixas etárias de cinco, seis e sete anos de idade, correspondendo às seguintes subtarefas: segmentação de frases de duas palavras (T1_2 palavras) aplicada para os sujeitos de cinco, seis e sete anos; segmentação de frases de três palavras (T1_3 palavras) para as idades de cinco e sete anos; segmentação de frases de quatro palavras (T1_4 palavras) para as idades de cinco e sete anos; segmentação de frases de cinco palavras (T1_5 palavras) para a idade de sete anos; segmentação de frases de seis palavras (T1_6 palavras) para a idade de sete anos; e segmentação de frases de sete palavras (T1_7 palavras) para a idade de sete anos.

Também foram aplicadas subtarefas como realismo nominal (T2) para as idades de cinco, seis e sete anos; detecção de rimas em palavras dissílabas (T3 dissílabas) para as idades de cinco, seis e sete anos; e detecção de rimas em palavras trissílabas (T3 trissílabas) para as idades de cinco, seis e sete anos.

Aplicaram-se subtarefas silábicas como: síntese silábica em palavras dissílabas (T4 dissílabas) para as idades de cinco, seis e sete anos; síntese silábica em palavras trissílabas (T4 trissílabas) para as idades de cinco, seis e sete anos; síntese silábica em palavras quadrissílabas (T4 quadrissílabas) para as idades de cinco, seis e sete anos; segmentação silábica em palavras dissílabas (T5 dissílabas) para as idades de cinco, seis e sete anos; segmentação silábica em palavras trissílabas (T5 trissílabas) para as idades de cinco, seis e sete anos; segmentação silábica em palavras quadrissílabas (T5 quadrissílabas) para as idades de cinco, seis e sete anos; detecção de sílaba em palavras com sílabas iguais em posição inicial (T6 inicial) para as idades de cinco, seis e sete anos; detecção de sílaba em palavras com sílabas iguais em posição final (T6 final) para as idades de cinco, seis e sete anos; detecção de sílaba em palavras com sílabas iguais em posição medial (T6 medial) para as idades de cinco, seis e sete anos; reversão silábica em palavras dissílabas (T7 dissílabas) para as idades de seis e sete anos; reversão silábica em palavras trissílabas (T7 trissílabas) para a idade de sete anos; e reversão silábica em palavras quadrissílabas (T7 quadrissílabas) para a idade de sete anos.

As subtarefas fonêmicas envolviam: exclusão de fonema em início de palavra (T8 inicial) para a idade de sete anos; exclusão de fonema no meio de palavra (T8 medial) para a idade de sete anos; exclusão de fonema em final de palavra (T8 final) para a idade de sete anos; detecção de fonemas em palavras com fonemas iguais na posição inicial (T9 inicial) para as idades de cinco, seis e sete anos; detecção de fonemas em palavras com fonemas iguais na posição final (T9 final) para as idades de seis e sete anos; detecção de fonemas em palavras com fonemas iguais na posição medial (T9 medial) para a idade de sete anos; síntese fonêmica em palavras de três fonemas (T10_3 fonemas) para a idade de sete anos; síntese fonêmica em palavras de quatro fonemas (T10_4 fonemas) para a idade de sete anos; síntese fonêmica em palavras de cinco fonemas (T10_5 fonemas) para a idade de sete anos; síntese fonêmica em palavras de seis fonemas (T10_6 fonemas) para a idade de sete anos; segmentação fonêmica em palavras de três fonemas (T11_3 fonemas) para a idade de sete anos; segmentação fonêmica em palavras de quatro fonemas (T11_4 fonemas) para a idade de sete anos; segmentação fonêmica em palavras de cinco fonemas (T11_5 fonemas) para a idade de sete anos; e reversão fonêmica em palavras de dois e três fonemas (T12_2 e 3 fonemas) para a idade de sete anos.

A aplicação do PTCF foi oral e suas respostas analisadas pelos critérios de escores, tendo, para cada item, duas tentativas de resposta: dois pontos para a resposta correta na primeira tentativa, um ponto para a resposta correta na segunda tentativa, ou zero para erro nas duas tentativas. Ocorria a suspensão da subtarefa após três erros consecutivos. Poderia ter um máximo de dez pontos computados para as subdivisões de cada tarefa, não sendo possível somar os escores de cada subdivisão, uma vez que cada um deles estava representando determinado nível de complexidade dentro da mesma tarefa.

Para possibilitar a análise dos dados e comparação entre os dois testes utilizados, nesta pesquisa, foi estabelecida uma nota de zero a 100 em cada subtarefa do PTCF. Tal nota corresponde a uma média percentual calculada da seguinte forma: número de pontos obtidos, divididos por dez 
(número máximo de pontos a serem obtidos em cada sub-tarefa) e multiplicados por 100 .

Foi estabelecido como percentual esperado (valor de referência) uma nota a partir de 50 pontos em cada subtarefa para um bom desempenho em consciência fonológica. Este percentual esperado foi comparado com a pontuação obtida pela amostra em cada grupo separadamente.

As avaliações foram realizadas em dois dias distintos para cada criança. As sessões tinham duração de 30 minutos em média. No primeiro dia aplicou-se a avaliação de consciência fonológica e os sujeitos responderam as subtarefas até demonstrarem cansaço, desta forma, a aplicação do teste era suspensa e retomada em outro dia. No segundo dia, as crianças terminaram as tarefas restantes em consciência fonológica e nomearam as figuras do teste de vocabulário expressivo.

Quanto às considerações éticas, este estudo fez parte de dois projetos de pesquisa, aprovados pelo Comitê de Ética em Pesquisa da Universidade Federal de Santa Maria, com cadastro sob os números 0102.0.243.000-07 e 0103.0.243.000-07.

Para análise dos dados, foi realizada uma análise estatística dos resultados obtidos com as avaliações de vocabulário expressivo e com as avaliações de consciência fonológica no GC e no GE. Cada grupo foi subdividido conforme as três idades estudadas. Foram utilizados dois testes estatísticos. O primeiro comparou, para cada grupo separadamente, o desempenho nos testes de consciência fonológica e vocabulário expressivo com os respectivos valores de referência através do teste de Wilcoxon para amostras relacionadas (para a análise dos resultados, foram consideradas apenas as diferenças estatisticamente significativas e inferiores ao valor de referência, não sendo consideradas as diferenças superiores ao valor de referência que foram significativas). $O$ segundo teste estatístico comparou os desempenhos entre os dois grupos utilizando o teste de Mann-Whitney. O nível de significância adotado para os testes estatísticos foi de $5 \%$, ou seja, $\mathrm{P}<0.05$.

\section{RESULTADOS}

As Tabelas a seguir apresentam a comparação dos resultados obtidos com os valores de referência para os testes realizados, por grupo e por faixa etária. Nestas tabelas também se verifica a comparação dos resultados entre os dois grupos (GC x GE) para cada faixa etária estudada.

A Tabela 1 apresenta os resultados para a faixa etária de cinco anos. Na Tabela 2, estão expostos os resultados encontrados com os grupos de seis anos de idade. A Tabela 3 apresenta os resultados referentes à faixa etária de sete anos.

Na Tabela 1, ao comparar os dois grupos, verifica-se diferença estatisticamente significativa entre o GC e GE para a idade de cinco anos, na qual o GE atingiu escores inferiores ao GC nas seguintes subtarefas do teste de consciência fonológica: síntese silábica em palavras quadrissílabas e detecção de fonema em início de palavra. Não houve diferença estatisticamente significativa entre os campos do vocabulário dos dois grupos de cinco anos.

Ao comparar os desempenhos da amostra com os valores de referência para a idade de cinco anos (Tabela 1), no GC encontrou-se diferença estatisticamente significativa com escores inferiores ao esperado no campo conceitual locais; e nas habilidades em segmentação de frases em duas, três e quatro palavras; e detecção de sílabas no meio de palavras. No GE encontrouse diferença significativa com escores inferiores ao esperado no campo conceitual locais; e nas habilidades em segmentação de frases em quatro palavras; detecção de sílabas no início, fim e meio de palavras; e detecção de fonemas em início de palavras.

$\mathrm{Na}$ Tabela 2, ao se comparar o GC com o GE na idade de seis anos, não foi verificada diferença estatisticamente significativa entre os grupos.

A comparação dos desempenhos das crianças de seis anos com os valores de referência esperados para esta idade está exposta na Tabela 2. Para o GC, encontrou-se diferença significativa com escores inferiores ao esperado no campo conceitual alimentos. No GE, encontrou-se diferença significativa com escores inferiores ao esperado nos campos conceituais alimentos e formas e cores.

Ao analisar a Tabela 3, envolvendo os sujeitos com sete anos de idade, comparando os dois grupos, os resultados estatisticamente significativos mostram que o GE atingiu uma pontuação inferior ao GC nas seguintes tarefas: no campo conceitual brinquedos e instrumentos musicais; na subtarefa em detecção de sílaba em final de palavra; e segmentação fonêmica em palavras de cinco fonemas.

Nesta Tabela, ao comparar os desempenhos com os valores de referência para a idade de sete anos, no GC, encontrou-se diferença significativa com escores inferiores ao esperado nos campos conceituais alimentos e locais. No GE, todas as variáveis atingiram os percentuais esperados, sem desvios significativos dos valores de referência. 
Tabela 1 - Análise comparativa dos resultados obtidos com os valores de referência, por grupo e para a idade de cinco anos, e comparação destes resultados entre os dois grupos de cinco anos de idade

\begin{tabular}{|c|c|c|c|c|c|c|c|c|c|c|c|c|}
\hline \multirow{2}{*}{ Variável } & \multirow{2}{*}{ VR } & \multicolumn{5}{|c|}{ GRUPO CONTROLE - IDADE 5 ANOS } & \multicolumn{5}{|c|}{ GRUPO ESTUDO - IDADE 5 ANOS } & \multirow{2}{*}{ Valor-P** } \\
\hline & & $\mathbf{N}$ & Média & D.P. & Mediana & Valor-p* & $\mathbf{N}$ & Média & D.P. & Mediana & Valor-p* & \\
\hline Vestuário & 65 & 12 & 73.33 & 8.88 & 70.00 & $\mathrm{p}=0.005$ & 10 & 62.00 & 25.73 & 70.00 & $\mathrm{p}=0.813$ & $\mathrm{P}=0.322$ \\
\hline Animais & 60 & 12 & 75.00 & 12.83 & 76.50 & $\mathrm{p}=0.006$ & 10 & 72.50 & 22.32 & 76.50 & $P=0.152$ & $P=0.947$ \\
\hline Alimentos & 70 & 12 & 63.33 & 14.40 & 67.00 & $\mathrm{p}=0.212$ & 10 & 60.10 & 18.45 & 67.00 & $P=0.178$ & $P=0.762$ \\
\hline Meios de Transporte & 50 & 12 & 74.50 & 10.03 & 73.00 & $p<0.001$ & 10 & 65.60 & 17.24 & 68.50 & $P=0.418$ & $P=0.307$ \\
\hline Móveis e utensílios & 60 & 12 & 72.92 & 7.66 & 71.00 & $p<0.001$ & 10 & 64.10 & 18.14 & 69.00 & $P=0.127$ & $P=0.217$ \\
\hline Profissões & 20 & 12 & 40.83 & 14.43 & 45.00 & $\mathrm{p}=0.219$ & 10 & 38.00 & 23.94 & 40.00 & $P=0.732$ & $P=0.790$ \\
\hline Locais & 50 & 12 & 26.33 & 15.49 & 29.00 & $\mathrm{p}<0.001^{*}$ & 10 & 28.40 & 23.07 & 25.00 & $P=0.002^{*}$ & $P=0.921$ \\
\hline Formas e cores & 30 & 12 & 61.67 & 24.80 & 65.00 & $p=0.340$ & 10 & 64.00 & 24.59 & 65.00 & $P=0.516$ & $P=0.999$ \\
\hline $\begin{array}{l}\text { Brinquedos e } \\
\text { instrumentos }\end{array}$ & 40 & 12 & 56.58 & 18.51 & 54.00 & $\mathrm{p}=0.999$ & 10 & 50.70 & 24.42 & 54.00 & $P=0.428$ & $P=0.814$ \\
\hline T1_2 palavras & 50 & 12 & 21.67 & 27.58 & 10.00 & $p=0.010^{*}$ & 10 & 34.00 & 36.58 & 30.00 & $P=0.217$ & $P=0.444$ \\
\hline T1_3 palavras & 50 & 12 & 27.50 & 29.27 & 20.00 & $\mathrm{p}=0.034^{*}$ & 10 & 26.67 & 30.00 & 20.00 & $P=0.063$ & $P=0.855$ \\
\hline T1_4 palavras & 50 & 12 & 8.33 & 13.37 & 0.00 & $\mathrm{p}<0.001^{*}$ & 10 & 14.44 & 16.67 & 10.00 & $P=0.004^{\star}$ & $P=0.340$ \\
\hline $\mathrm{T} 2$ & 50 & 12 & 70.83 & 15.64 & 75.00 & $p=0.004$ & 10 & 55.00 & 18.41 & 60.00 & $P=0.481$ & $P=0.063$ \\
\hline T3 dissílabas & 50 & 12 & 62.50 & 25.98 & 60.00 & $\mathrm{p}=0.097$ & 10 & 48.00 & 16.19 & 45.00 & $P=0.789$ & $P=0.052$ \\
\hline T3 trissílabas & 50 & 12 & 64.17 & 23.92 & 60.00 & $\mathrm{P}=0.079$ & 10 & 45.00 & 25.93 & 50.00 & $P=0.656$ & $P=0.059$ \\
\hline T4 dissílabas & 50 & 12 & 95.83 & 9.00 & 100.00 & $P<0.001$ & 10 & 91.00 & 9.94 & 95.00 & $P=0.002$ & $P=0.205$ \\
\hline T4 trissílabas & 50 & 12 & 91.67 & 8.35 & 90.00 & $P<0.001$ & 10 & 86.00 & 18.38 & 95.00 & $P=0004$ & $P=0.752$ \\
\hline T4 quadrissílabas & 50 & 12 & 88.33 & 19.46 & 100.00 & $P=0.001$ & 10 & 71.00 & 19.12 & 65.00 & $P=0.012$ & $\mathrm{P}=0.034^{\star *}$ \\
\hline T5 dissílabas & 50 & 12 & 90.83 & 15.05 & 100.00 & $P=0.001$ & 10 & 86.00 & 19.55 & 95.00 & $P=0.004$ & $P=0.539$ \\
\hline T5 trissílabas & 50 & 12 & 83.33 & 22.70 & 95.00 & $P=0.002$ & 10 & 70.00 & 34.32 & 85.00 & $P=0.090$ & $P=0.320$ \\
\hline T5 quadrissílabas & 50 & 12 & 70.83 & 28.43 & 70.00 & $P=0.048$ & 10 & 38.00 & 41.58 & 30.00 & $P=0.395$ & $P=0.065$ \\
\hline T6 inicial & 50 & 12 & 45.83 & 23.92 & 40.00 & $P=0.384$ & 10 & 33.00 & 12.52 & 35.00 & $P=0.008^{*}$ & $P=0.222$ \\
\hline T6 final & 50 & 12 & 32.50 & 28.00 & 20.00 & $P=0.068$ & 10 & 22.00 & 17.51 & 20.00 & $P=0.002^{*}$ & $P=0.395$ \\
\hline T6medial & 50 & 12 & 29.17 & 22.34 & 30.00 & $P=0.016^{*}$ & 10 & 20.00 & 21.08 & 20.00 & $P=0.008^{*}$ & $P=0.323$ \\
\hline T9 inicial & 50 & 12 & 49.17 & 25.75 & 55.00 & $\mathrm{P}=0.730$ & 10 & 20.00 & 18.86 & 20.00 & $P=0.006^{*}$ & $\mathrm{P}=0.009^{* *}$ \\
\hline
\end{tabular}

Legenda 1: T1_2 palavras - Segmentação de frases de duas palavras; T1_3 palavras - Segmentação de frases de três palavras; T1_4 palavras - Segmentação de frases de quatro palavras; T2- Realismo nominal; T3 - Detecção de rimas em palavras dissílabas e trissílabas; T4 - Síntese silábica em palavras dissílabas, trissílabas e quadrissílabas; T5 - Segmentação silábica em palavras dissílabas, trissílabas e quadrissílabas; T6 - Detecção de sílabas iguais em início, final e meio de palavras; T9 - Detecção de fonemas iguais em início de palavras; VR - valor de referência; N - número de sujeitos; D.P. - desvio padrão;

*Valor-p referente ao teste de Wilcoxon - valores significativos e inferiores ao esperado estão em negrito e com um asterisco

** Valor-p referente ao teste de Mann-Whitney - os valores em negrito e com dois asteriscos são aqueles em que a diferença entre os dois grupos foi significativa; o nível de significância adotado para os testes estatísticos foi de $5 \%$, ou seja, $P<0.05$.

Fonte: Befi-Lopes DM. Vocabulário. In: Andrade CRF, Befi-Lopes DM, Fernandes FDM, Wertzner HF. ABFW: teste de linguagem infantil nas áreas de fonologia, vocabulário, fluência e pragmática. Barueri: Pró-Fono; 2000. Cap 2.

\section{DISCUSSÃO}

Em relação às crianças de cinco anos, os participantes com desvio fonológico apresentaram escore inferior às crianças típicas nas tarefas de consciência fonológica denominadas síntese silábica em palavras quadrissílabas e detecção de fonema em início de palavra. Resultados semelhantes em consciência fonológica foram encontrados em outra pesquisa ${ }^{14}$, com crianças entre quatro e oito anos de idade na qual, na análise geral dos dados, os participantes com desvio fonológico apresentaram pior desempenho do que as crianças com desenvolvimento de fala normal. Esta pesquisa também encontrou que a subtarefa de detecção de fonema em início de palavra foi uma das subtarefas que as crianças com desvio fonológico apresentaram desempenho inferior ao dos outros participantes estudados.
Quanto ao vocabulário, não foi verificada diferença entre os dois grupos de cinco anos. Desta forma, tanto crianças com desvio fonológico quanto crianças típicas apresentaram desempenhos semelhantes.

Ao comparar o GC com o GE na idade de seis anos, não foi verificada diferença estatisticamente significativa entre os grupos. Ambos os grupos apresentaram desempenhos semelhantes nas tarefas avaliadas. Estes achados concordam com os encontrados em outro estudo ${ }^{12}$ realizado com crianças entre seis e oito anos de idade, uma vez que as crianças com desvio fonológico não diferiram das crianças sem desvio fonológico no desempenho das provas de consciência fonológica. Os autores procuraram explicar este fato considerando que os participantes da amostra estudada estavam em contato com a linguagem escrita e a consciência fonológica estava em processo de 
Tabela 2 - Análise comparativa dos resultados obtidos com os valores de referência, por grupo e para a idade de seis anos, e comparação destes resultados entre os dois grupos de seis anos de idade

\begin{tabular}{|c|c|c|c|c|c|c|c|c|c|c|c|c|}
\hline \multirow{2}{*}{ Variável } & \multirow[b]{2}{*}{ VR } & \multicolumn{5}{|c|}{ GRUPO CONTROLE - IDADE 6 ANOS } & \multicolumn{5}{|c|}{ GRUPO ESTUDO - IDADE 6 ANOS } & \multirow{2}{*}{ Valor-P** } \\
\hline & & $\mathbf{N}$ & Média & D.P. & Mediana & Valor-p* & $\mathbf{N}$ & Média & D.P. & Mediana & Valor-p* & \\
\hline Vestuário & 80 & 27 & 83.33 & 9.20 & 80.00 & $P=0.107$ & 10 & 79.00 & 11.01 & 80.00 & $P=1.000$ & $\mathrm{P}=0.312$ \\
\hline Animais & 70 & 27 & 86.93 & 7.74 & 87.00 & $P<0.001$ & 10 & 86.60 & 20.71 & 93.00 & $P=0.080$ & $\mathrm{P}=0.199$ \\
\hline Alimentos & 90 & 27 & 73.74 & 12.05 & 73.00 & $P<0.001^{*}$ & 10 & 74.00 & 9.51 & 73.00 & $P=0.004^{*}$ & $P=0.660$ \\
\hline Meios de transporte & 70 & 27 & 84.30 & 7.33 & 82.00 & $P<0.001$ & 10 & 81.00 & 11.83 & 82.00 & $P=0.027$ & $P=0.558$ \\
\hline Móveis e utensílios & 65 & 27 & 78.70 & 5.07 & 79.00 & $P<0.001$ & 10 & 76.10 & 6.23 & 75.00 & $P=0.004$ & $P=0.187$ \\
\hline Profissões & 45 & 27 & 57.04 & 16.36 & 60.00 & $P<0.001$ & 10 & 47.00 & 23.12 & 60.00 & $P=0.731$ & $P=0.327$ \\
\hline Locais & 70 & 27 & 61.41 & 20.04 & 67.00 & $P=0.113$ & 10 & 57.50 & 18.63 & 62.50 & $P=0.098$ & $P=0.555$ \\
\hline Formas e cores & 85 & 27 & 82.22 & 9.74 & 80.00 & $P=0.134$ & 10 & 73.00 & 15.67 & 70.00 & $P=0.037^{*}$ & $P=0.087$ \\
\hline $\begin{array}{l}\text { Brinquedos e } \\
\text { instrumentos }\end{array}$ & 70 & 27 & 68.15 & 17.49 & 73.00 & $P=0.870$ & 10 & 70.90 & 17.30 & 77.50 & $P=0.820$ & $P=0.542$ \\
\hline T1_2 palavras & 50 & 27 & 44.44 & 35.66 & 50.00 & $P=0.364$ & 10 & 51.00 & 34.79 & 60.00 & $P=0.922$ & $P=0.664$ \\
\hline T2 & 50 & 27 & 81.11 & 14.76 & 80.00 & $P<0.001$ & 10 & 83.00 & 11.60 & 80.00 & $P=0.002$ & $P=0.818$ \\
\hline T3 dissílabas & 50 & 27 & 75.93 & 19.27 & 80.00 & $\mathrm{P}<0.001$ & 10 & 63.00 & 23.59 & 65.00 & $P=0.135$ & $\mathrm{P}=0.128$ \\
\hline T3 trissílabas & 50 & 27 & 71.11 & 19.08 & 70.00 & $P<0.001$ & 10 & 63.00 & 28.69 & 60.00 & $P=0.223$ & $\mathrm{P}=0.416$ \\
\hline T4 dissílabas & 50 & 27 & 98.15 & 5.57 & 100.00 & $P<0.001$ & 10 & 91.00 & 16.63 & 100.00 & $P=0.002$ & $P=0.143$ \\
\hline T4 trissílabas & 50 & 27 & 96.30 & 7.92 & 100.00 & $P<0.001$ & 10 & 97.00 & 4.83 & 100.00 & $P=0.002$ & $\mathrm{P}=0.784$ \\
\hline T4 quadrissílabas & 50 & 27 & 94.44 & 12.81 & 100.00 & $P<0.001$ & 10 & 84.00 & 26.33 & 100.00 & $P=0.010$ & $\mathrm{P}=0.212$ \\
\hline T5 dissílabas & 50 & 27 & 95.56 & 10.50 & 100.00 & $P<0.001$ & 10 & 92.00 & 13.17 & 100.00 & $P=0.002$ & $P=0.228$ \\
\hline T5 trissílabas & 50 & 27 & 97.41 & 6.56 & 100.00 & $P<0.001$ & 10 & 97.00 & 6.75 & 100.00 & $P=0.002$ & $P=0.749$ \\
\hline T5 quadrissílabas & 50 & 27 & 88.15 & 19.02 & 100.00 & $P<0.001$ & 10 & 88.00 & 16.87 & 95.00 & $P=0.004$ & $P=0.868$ \\
\hline T6 inicial & 50 & 27 & 76.67 & 20.57 & 80.00 & $P<0.001$ & 10 & 60.00 & 33.67 & 65.00 & $P=0.305$ & $P=0.241$ \\
\hline T6 final & 50 & 27 & 60.37 & 24.10 & 60.00 & $P=0.047$ & 10 & 60.00 & 24.04 & 60.00 & $P=0.219$ & $P=0.999$ \\
\hline T6medial & 50 & 27 & 52.59 & 32.89 & 60.00 & $P=0.652$ & 10 & 54.00 & 30.26 & 60.00 & $P=0.648$ & $P=0.889$ \\
\hline T7 dissílabas & 50 & 27 & 42.22 & 37.76 & 20.00 & $P=0.392$ & 10 & 37.00 & 22.14 & 25.00 & $P=0.125$ & $P=0.958$ \\
\hline T9 inicial & 50 & 27 & 56.30 & 32.48 & 60.00 & $P=0.338$ & 10 & 52.00 & 18.74 & 50.00 & $P=0.682$ & $P=0.756$ \\
\hline T9 final & 50 & 27 & 42.96 & 28.80 & 40.00 & $P=0.196$ & 10 & 51.00 & 18.53 & 55.00 & $P=0.945$ & $P=0.261$ \\
\hline
\end{tabular}

Legenda 2: T1_2 palavras - Segmentação de frases de duas palavras; T2- Realismo nominal; T3 - Detecção de rimas em palavras dissílabas e trissílabas; T4 - Síntese silábica em palavras dissílabas, trissílabas e quadrissílabas; T5 - Segmentação silábica em palavras dissílabas, trissílabas e quadrissílabas; T6 - Detecção de sílabas iguais em início, final e meio de palavras; T7 - Reversão silábica em palavras dissílabas; T9 - Detecção de fonemas iguais em início e final de palavras; VR - valor de referência; N - número de sujeitos; D.P. - desvio padrão;

* Valor-p referente ao teste de Wilcoxon - valores significativos e inferiores ao esperado estão em negrito e com um asterisco; ${ }^{* \star}$ Valor-p referente ao teste de Mann-Whitney - os valores em negrito e com dois asteriscos são aqueles em que a diferença entre os dois grupos foi significativa; o nível de significância adotado para os testes estatísticos foi de $5 \%$, ou seja, $\mathrm{P}<0.05$.

Fonte: Befi-Lopes DM. Vocabulário. In: Andrade CRF, Befi-Lopes DM, Fernandes FDM, Wertzner HF. ABFW: teste de linguagem infantil nas áreas de fonologia, vocabulário, fluência e pragmática. Barueri: Pró-Fono; 2000. Cap 2.

aquisição. Na presente pesquisa, tais constatações concordam em parte com o estudo citado, uma vez que algumas das crianças estudadas com seis anos estavam em contato com a escrita e as demais estavam na educação infantil.

Ao comparar os grupos de crianças com sete anos de idade, o GE atingiu uma pontuação inferior ao GC no campo conceitual brinquedos e instrumentos musicais; na subtarefa em detecção de sílaba em final de palavra; e segmentação fonêmica em palavras de cinco fonemas. Em relação aos resultados de consciência fonológica, uma pesquisa ${ }^{14}$ encontrou resultados semelhantes nestas subtarefas, favorecendo um melhor desempenho para os participantes com desenvolvimento de fala normal. Porém, a pesquisa citada anteriormente ${ }^{12}$ também analisou a faixa etária de sete anos e não encontrou diferenças no desempenho dos dois grupos.
Os resultados da comparação dos desempenhos da amostra com os valores de referência para cada idade estudada e para cada grupo serão discutidos a seguir.

Ambos os grupos de cinco anos apresentaram dificuldades (desempenhos inferiores ao esperado estatisticamente significativos) nas mesmas habilidades (com variações de complexidade), com exceção do GE, que teve desempenho estatisticamente inferior na subtarefa de detecção de fonema em início de palavra. Concordando com estes achados, a literatura da área ${ }^{14}$ mostra que crianças com desvio fonológico apresentaram maior dificuldade com as tarefas fonêmicas, apontando para uma relação direta entre o desenvolvimento fonológico e a consciência fonêmica. Os aspectos fonêmicos da consciência fonológica apresentam um grau mais alto de dificuldade em relação aos aspectos silábicos, evidenciando 
Tabela 3 - Análise comparativa dos resultados obtidos com os valores de referência, por grupo e para a idade de sete anos, e comparação destes resultados entre os dois grupos de sete anos de idade

\begin{tabular}{|c|c|c|c|c|c|c|c|c|c|c|c|c|}
\hline \multirow{2}{*}{ Variável } & \multirow{2}{*}{ VR } & \multicolumn{5}{|c|}{ GRUPO CONTROLE - IDADE 7 ANOS } & \multicolumn{5}{|c|}{ GRUPO ESTUDO - IDADE 7 ANOS } & \multirow{2}{*}{ Valor-P** } \\
\hline & & $\mathbf{N}$ & Média & D.P. & Mediana & Valor-p* & $\mathbf{N}$ & Média & D.P. & Mediana & Valor-p* & \\
\hline Vestuário & $>80$ & 11 & 81.82 & 8.74 & 80.00 & $\mathrm{P}=0.727$ & 4 & 80.00 & 8.16 & 80.00 & $P=1.00$ & $P=0.677$ \\
\hline Animais & $>70$ & 11 & 89.09 & 6.02 & 87.00 & $P=0.001$ & 4 & 90.25 & 6.50 & 87.00 & $P=0.125$ & $P=0.945$ \\
\hline Alimentos & $>90$ & 11 & 78.27 & 7.42 & 80.00 & $\mathrm{P}=0.001^{*}$ & 4 & 71.50 & 12.77 & 76.50 & $P=0.125$ & $P=0.341$ \\
\hline $\begin{array}{l}\text { Meios de } \\
\text { Transporte }\end{array}$ & $>70$ & 11 & 86.09 & 6.19 & 91.00 & $P=0.001$ & 4 & 82.00 & 7.35 & 82.00 & $P=0.125$ & $P=0.284$ \\
\hline Móveis e utensílios & $>65$ & 11 & 82.00 & 5.57 & 83.00 & $P=0.001$ & 4 & 77.00 & 2.31 & 77.00 & $P=0.125$ & $P=0.058$ \\
\hline Profissões & $>45$ & 11 & 61.82 & 17.22 & 60.00 & $P=0.006$ & 4 & 62.50 & 5.00 & 60.00 & $P=0.125$ & $P=0.590$ \\
\hline Locais & $>70$ & 11 & 53.09 & 15.99 & 50.00 & $P=0.008^{*}$ & 4 & 66.50 & 23.57 & 75.00 & $\mathrm{P}=0.999$ & $P=0.257$ \\
\hline Formas e cores & $>85$ & 11 & 85.45 & 12.14 & 90.00 & $P=0.683$ & 4 & 77.50 & 12.58 & 80.00 & $P=0.500$ & $P=0.220$ \\
\hline $\begin{array}{l}\text { Brinquedos e } \\
\text { instrumentos }\end{array}$ & $>70$ & 11 & 83.55 & 10.78 & 82.00 & $P=0.017$ & 4 & 75.25 & 4.50 & 73.00 & $P=0.125$ & $\mathrm{P}=0.032^{* *}$ \\
\hline T1_2 palavras & 50 & 11 & 69.09 & 41.34 & 80.00 & $P=0.228$ & 4 & 65.00 & 30.00 & 80.00 & $P=0.625$ & $P=0.409$ \\
\hline T1_3 palavras & 50 & 11 & 63.64 & 30.42 & 80.00 & $P=0.158$ & 4 & 50.00 & 25.82 & 50.00 & $P=1.000$ & $P=0.385$ \\
\hline T1_4 palavras & 50 & 11 & 62.73 & 39.27 & 80.00 & $P=0.266$ & 4 & 45.00 & 44.35 & 40.00 & $P=0.999$ & $P=0.464$ \\
\hline T1_5 palavras & 50 & 11 & 58.18 & 46.00 & 80.00 & $P=0.617$ & 4 & 30.00 & 34.64 & 20.00 & $P=0.500$ & $P=0.281$ \\
\hline T1_6 palavras & 50 & 11 & 46.36 & 42.25 & 60.00 & $P=0.570$ & 4 & 30.00 & 34.64 & 20.00 & $P=0.500$ & $P=0.640$ \\
\hline T1_7 palavras & 50 & 11 & 37.27 & 40.52 & 40.00 & $P=0.371$ & 4 & 20.00 & 40.00 & 0.00 & $P=0.250$ & $P=0.435$ \\
\hline T2 & 50 & 11 & 94.55 & 8.20 & 100.00 & $P=0.001$ & 4 & 90.00 & 14.14 & 95.00 & $P=0.125$ & $P=0.554$ \\
\hline T3 dissílabas & 50 & 11 & 86.36 & 16.29 & 90.00 & $P=0.002$ & 4 & 70.00 & 24.49 & 70.00 & $P=0.250$ & $P=0.154$ \\
\hline T3 trissílabas & 50 & 11 & 83.64 & 20.63 & 90.00 & $P=0.004$ & 4 & 67.50 & 29.86 & 70.00 & $P=0.375$ & $P=0.284$ \\
\hline T4 dissílabas & 50 & 11 & 100.00 & 0.00 & 100.00 & $P=0.001$ & 4 & 100.00 & 0.00 & 100.00 & $P=0.125$ & $P=1.000$ \\
\hline T4 trissílabas & 50 & 11 & 100.00 & 0.00 & 100.00 & $P=0.001$ & 4 & 97.50 & 5.00 & 100.00 & $P=0.125$ & $P=0.097$ \\
\hline T4 quadrissílabas & 50 & 11 & 100.00 & 0.00 & 100.00 & $P=0.001$ & 4 & 92.50 & 15.00 & 100.00 & $P=0.125$ & $P=0.097$ \\
\hline T5 dissílabas & 50 & 11 & 97.27 & 6.47 & 100.00 & $P=0.001$ & 4 & 100.00 & 0.00 & 100.00 & $P=0.125$ & $P=0.377$ \\
\hline T5 trissílabas & 50 & 11 & 96.36 & 6.74 & 100.00 & $P=0.001$ & 4 & 95.00 & 10.00 & 100.00 & $P=0.125$ & $P=0.933$ \\
\hline T5 quadrissílabas & 50 & 11 & 86.36 & 23.78 & 100.00 & $P=0.005$ & 4 & 87.50 & 9.57 & 85.00 & $P=0.125$ & $P=0.527$ \\
\hline T6 inicial & 50 & 11 & 86.36 & 16.29 & 90.00 & $P=0.001$ & 4 & 87.50 & 9.57 & 85.00 & $P=0.125$ & $P=0.838$ \\
\hline T6 final & 50 & 11 & 84.55 & 18.09 & 90.00 & $P=0.002$ & 4 & 57.50 & 20.62 & 60.00 & $P=0.625$ & $\mathrm{P}=0.028^{* \star}$ \\
\hline T6medial & 50 & 11 & 65.45 & 23.39 & 60.00 & $P=0.076$ & 4 & 50.00 & 14.14 & 55.00 & $P=0.999$ & $P=0.204$ \\
\hline T7 dissílabas & 50 & 11 & 68.18 & 35.16 & 80.00 & $P=0.098$ & 4 & 47.50 & 41.13 & 45.00 & $P=0.999$ & $P=0.391$ \\
\hline T7 trissílabas & 50 & 11 & 49.09 & 39.61 & 60.00 & $P=0.895$ & 4 & 37.50 & 35.00 & 20.00 & $P=0.999$ & $P=0.894$ \\
\hline T7 quadrissílabas & 50 & 11 & 53.64 & 32.33 & 60.00 & $P=0.754$ & 4 & 20.00 & 0.00 & 20.00 & $P=0.125$ & $P=0.058$ \\
\hline T8 inicial & 50 & 11 & 62.73 & 36.63 & 80.00 & $P=0.236$ & 4 & 62.50 & 33.04 & 65.00 & $P=0.625$ & $P=0.842$ \\
\hline T8 final & 50 & 11 & 65.45 & 31.42 & 80.00 & $P=0.147$ & 4 & 65.00 & 31.09 & 75.00 & $P=0.500$ & $P=0.894$ \\
\hline T8medial & 50 & 11 & 65.45 & 45.69 & 100.00 & $P=0.344$ & 4 & 52.50 & 45.73 & 55.00 & $P=0.999$ & $P=0.487$ \\
\hline T9 inicial & 50 & 11 & 87.27 & 15.55 & 90.00 & $P=0.001$ & 4 & 77.50 & 26.30 & 85.00 & $P=0.250$ & $P=0.454$ \\
\hline T9 final & 50 & 11 & 69.09 & 33.30 & 80.00 & $P=0.141$ & 4 & 35.00 & 33.17 & 25.00 & $P=0.375$ & $P=0.085$ \\
\hline T9medial & 50 & 11 & 60.00 & 33.76 & 60.00 & $P=0.385$ & 4 & 25.00 & 19.15 & 30.00 & $P=0.125$ & $P=0.087$ \\
\hline T10_3 fonemas & 50 & 11 & 52.73 & 21.49 & 50.00 & $P=0.754$ & 4 & 40.00 & 14.14 & 35.00 & $P=0.375$ & $P=0.259$ \\
\hline T10_4 fonemas & 50 & 11 & 53.64 & 38.54 & 80.00 & $P=0.930$ & 4 & 30.00 & 20.00 & 20.00 & $P=0.250$ & $P=0.388$ \\
\hline T10_5 fonemas & 50 & 11 & 36.36 & 37.49 & 20.00 & $P=0.236$ & 4 & 5.00 & 10.00 & 0.00 & $P=0.125$ & $P=0.128$ \\
\hline T10_6 fonemas & 50 & 11 & 31.82 & 37.63 & 20.00 & $P=0.225$ & 4 & 12.50 & 18.93 & 5.00 & $\mathrm{P}=0.125$ & $P=0.378$ \\
\hline T11_3 fonemas & 50 & 11 & 50.91 & 41.82 & 70.00 & $P=0.824$ & 4 & 15.00 & 30.00 & 0.00 & $P=0.250$ & $P=0.112$ \\
\hline T11_4 fonemas & 50 & 11 & 47.27 & 46.71 & 60.00 & $P=0.727$ & 4 & 0.00 & 0.00 & 0.00 & $P=0.125$ & $P=0.076$ \\
\hline T11_5 fonemas & 50 & 11 & 41.82 & 38.42 & 50.00 & $P=0.385$ & 4 & 0.00 & 0.00 & 0.00 & $P=0.125$ & $P=0.047^{* *}$ \\
\hline T12_2 e 3 fonemas & 50 & 11 & 40.00 & 34.35 & 40.00 & $P=0.424$ & 4 & 10.00 & 11.55 & 10.00 & $P=0.125$ & $P=0.176$ \\
\hline
\end{tabular}

Legenda 3: T1 - Segmentação de frases de 2, 3, 4, 5, 6 e 7 palavras; T2- Realismo nominal; T3 - Detecção de rimas em palavras dissílabas e trissílabas; T4 - Síntese silábica em palavras dissílabas, trissílabas e quadrissílabas; T5 - Segmentação silábica em palavras dissílabas, trissílabas e quadrissílabas; T6 - Detecção de sílabas iguais em início, final e meio de palavras; T7 - Reversão silábica em palavras dissílabas, trissílabas e quadrissílabas; T8 - Exclusão de fonema em início, meio e final de palavra; T9 - Detecção de fonemas iguais em início, final e meio de palavras; T10 - síntese fonêmica em palavras de 3, 4, 5 e 6 fonemas; T11 - Segmentação fonêmica em palavras de 3, 4 e 5 fonemas; T12 - Reversão fonêmica em palavras de 2 e 3 fonemas; VR - valor de referência; $\mathrm{N}$ - número de sujeitos; D.P. - desvio padrão;

*Valor-p referente ao teste de Wilcoxon - valores significativos e inferiores ao esperado estão em negrito e com um asterisco;

** Valor-p referente ao teste de Mann-Whitney - os valores em negrito e com dois asteriscos são aqueles em que a diferença entre os dois grupos foi significativa; o nível de significância adotado para os testes estatísticos foi de $5 \%$, ou seja, $P<0.05$.

Fonte: Befi-Lopes DM. Vocabulário. In: Andrade CRF, Befi-Lopes DM, Fernandes FDM, Wertzner HF. ABFW: teste de linguagem infantil nas áreas de fonologia, vocabulário, fluência e pragmática. Barueri: Pró-Fono; 2000. Cap 2. 
que a consciência silábica é adquirida antes da consciência fonêmica ${ }^{8}$.

A dificuldade apresentada pelas crianças de cinco anos com a segmentação de frases em palavras também foi verificada em outro estudo ${ }^{28}$, que encontrou dados semelhantes, e relacionou este fato a um déficit educacional dessa amostra como fator causal, o que também poderia ter relação com a origem educacional da amostra estudada no presente estudo.

Para a idade de seis anos, as crianças do GE apresentaram diferença significativa com escores inferiores ao esperado nos campos conceituais alimentos e formas e cores. As crianças do GC apresentaram diferença significativa com escores inferiores ao esperado no campo conceitual alimentos. Portanto, a dificuldade foi maior para o GE, uma vez que este teve dificuldade com um campo conceitual a mais que o GC, o campo formas e cores.

Os participantes de sete anos do GE atingiram os percentuais esperados em todas as variáveis estudadas. Por sua vez, as crianças do GC apresentaram escores inferiores ao esperado nos campos conceituais alimentos e locais.. Estes resultados apontam uma maior dificuldade do GC com estes campos conceituais, uma vez que as crianças com desvio fonológico tiveram um desempenho dentro do esperado.

Conforme pesquisa ${ }^{29}$, destaca-se a importância de estimular as habilidades em consciência fonológica nas crianças pré-escolares e, principalmente, nas com desvio fonológico. Pois estas últimas podem ser consideradas de risco para a presença de futuras dificuldades no desenvolvimento da linguagem.

No presente estudo, é interessante observar que as idades de seis e sete anos não apresentaram desempenhos estatisticamente inferiores ao esperado pelos valores de referência nas subtarefas em consciência fonológica. Tal fato pode ser explicado pelo aumento da idade dos sujeitos ${ }^{1,3,11}$ e pela influência da alfabetização ${ }^{5-7}$. Resultados ${ }^{11}$ em que os sujeitos com desvio fonológico, com idade de seis anos ou mais, apresentaram melhor desempenho nas tarefas de consciência fonológica, seriam possivelmente pela maior exposição à linguagem escrita. Estes dados concordam com este estudo, pois alguns sujeitos de seis anos e todos de sete anos haviam sido expostos à escrita e este fator poderia ter influenciado no desempenho em consciência fonológica.

Para o GE de cinco anos de idade, o único campo conceitual inferior significativamente foi o de locais. Estes achados concordam com uma pesquisa ${ }^{30}$ com crianças com desvio fonológico de três a oito anos de idade, em que este campo conceitual atingiu a maior porcentagem de alteração entre as crianças, independente da gravidade do desvio (82,92\% das crianças da amostra apresentaram este campo alterado). Os autores atribuem tal fato a uma dificuldade em identificar as figuras e em compreendê-las, relacionando fatores como falta de clareza visual, pouca familiaridade e objetos infrequentes ao cotidiano dos participantes avaliados. Esse campo também esteve alterado em outro estudo ${ }^{31}$ envolvendo crianças com desvio fonológico de cinco e seis anos de idade. A dificuldade com esse campo conceitual poderia estar relacionada a fatores importantes na nomeação, como características culturais e de desenvolvimento, familiaridade e complexidade visual das figuras, uma vez que as crianças tendem a nomear com mais precisão objetos vivenciados com frequência no seu cotidiano ou com mais clareza nos detalhes visuais ${ }^{32}$. O fator socioeconômico também poderia ter influenciado no desenvolvimento do vocabulário, segundo pesquisa ${ }^{24}$ que destaca a importância da escolaridade das pessoas que constituem o ambiente da criança, sendo que, quanto mais escolarizados, maior é a riqueza dos estímulos oferecidos a ela. Este fator poderia ter influenciado no desempenho dos sujeitos da amostra estudada, uma vez que eram provenientes de um serviço público e escolas públicas de baixo nível sócio-econômico.

Deve-se levar em consideração que o processo de nomeação envolve três estágios: primeiro ocorre a identificação do objeto (descrição física), depois a ativação do nome (as características semânticas do objeto são acessadas) por fim, o nome da figura é ativado e pronunciado ${ }^{33}$. Convergindo com estes achados, o baixo reconhecimento de figuras teria relação por serem menos familiares, ou complicadas e cheias de detalhes sendo mais difíceis para a criança identificar ${ }^{33}$. Portanto, a qualidade visual das figuras do teste poderia influenciar no desempenho em vocabulário expressivo, como verificado em outra pesquisa ${ }^{30}$, que utilizou 0 mesmo instrumento de avaliação de vocabulário e descreveu a dificuldade encontrada pelos sujeitos para compreender o significado de alguns desenhos e, consequentemente, para denominá-los. Tal situação poderia ter ocorrido no presente estudo quando os sujeitos apresentaram dificuldades para nomear campos conceituais como locais, alimentos e formas e cores.

Pesquisas ${ }^{31,33}$ corroboram estes achados, uma vez que as crianças estudadas mostraram desempenhos satisfatórios em categorias que incluíam itens frequentemente encontrados no ambiente da criança, como na designação dos campos 
conceituais animais, meios de transporte, móveis e utensílios domésticos ou brinquedos e instrumentos musicais.

Desta forma, os achados levam a acreditar em uma relação entre consciência fonológica e vocabulário expressivo, ambos contribuindo para o desenvolvimento da linguagem. Estes resultados concordam com as constatações de outros autores ${ }^{17,25}$ que também afirmam a existência desta interrelação.

\section{CONCLUSÃO}

As crianças com desvio fonológico, de uma maneira geral, atingiram um desempenho inferior aos participantes com aquisição típica de linguagem nas tarefas analisadas.

Quanto à influência da idade no desempenho dos grupos, tanto em vocabulário expressivo quanto em consciência fonológica, as crianças de cinco anos, de ambos os grupos, apresentaram dificuldades nas mesmas tarefas, embora com variações de complexidade entre elas. A exceção ocorreu quando as crianças com desvio fonológico apresentaram maior dificuldade com a subtarefa de detecção de fonema em início de palavra do que as crianças típicas. Já os sujeitos de seis e sete anos de idade, de ambos os grupos, apresentaram um desempenho adequado nas tarefas em consciência fonológica, mas apresentaram dificuldades em vocabulário expressivo. Portanto, pode-se inferir que há influência da idade no desempenho destas habilidades, para ambos os grupos. Pois, com o aumento da idade, os participantes apresentaram dificuldades apenas em vocabulário e não mais em consciência fonológica.

Conclui-se desta forma, que existe relação entre consciência fonológica e vocabulário expressivo nos participantes avaliados, e estes dois subsistemas contribuem para o desenvolvimento da linguagem.

\begin{abstract}
Purpose: to compare the performance of children with phonological disorder and with typical language acquisition through tests of expressive vocabulary and phonological awareness, and to evaluate the age influence. Method: subjects divided into control group (CG) and study group (SG); aged between five and seven years old; tests of expressive vocabulary and phonological awareness were applied; the obtained data were statistically analyzed. Results: comparing both groups, SG children aged five and seven years old showed some significantly lower results than the ones from CG; however, there was no difference between both groups for six years-old children in both skills of phonological awareness and vocabulary. Concerning the scores, lower than expected, the five years-old children presented difficulties in the same tasks of expressive vocabulary and phonological awareness, with complexity variations, except for the SG that showed a bigger difficulty to detect phoneme in word beginning. The six and seven years-old subjects had difficulties only with expressive vocabulary. Conclusion: children with phonological disorder showed lower performance in some skills of vocabulary and phonological awareness, when compared to children with typical development. It can also be concluded that age influences the performance in these skills for both groups.
\end{abstract}

KEYWORDS: Language Tests; Vocabulary; Semantics; Child Language; Language Development

\section{REFERÊNCIAS}

1. Vieira MG, Mota HB, Keske-Soares M. Relação entre idade, grau de severidade do desvio fonológico e consciência fonológica. Rev Soc Bras Fonoaudiol. 2004; 9(3): 144-50.

2. Yavas M, Hernandorena CL, Lamprecht RR. Avaliação fonológica da criança: reeducação e terapia. Porto Alegre: Artes Médicas; 1991.

3. Cielo CA. Habilidades em consciência fonológica em crianças de 4 a 8 anos de idade. Pró-fono. 2002; 14(3): 301-12.

4. Cielo CA. Avaliação de habilidades em consciência fonológica. J Bras Fonoaudiol. 2003; 4(16): 163-74.

5. Gindri G, Keske-Soares M, Mota HB. Memória de trabalho, consciência fonológica e hipótese de escrita. Pró-Fono. 2007; 19(3): 313-22.

6. Dambrowski AB, Martins CL, Theodoro JL, Gomes E. Influência da consciência fonológica na 
escrita de pré-escolares. Rev CEFAC. 2008; 10(2): 175-81.

7. Zuanetti PA, Schneck APC, Manfredi AKS. Consciência fonológica e desempenho escolar. Rev CEFAC. 2008; 10(2): 168-74.

8. Ettore B, Mangueira ASC, Dias BDG, Teixeira JB, Nemr K. Relação entre consciência fonológica e os níveis de escrita de escolares da $1^{\text {a }}$ série do ensino fundamental de escola pública do município de Porto Real - RJ. Rev CEFAC. 2008; 10(2): 149-57.

9. Moura SRS, Mezzomo CL, Cielo CA. Estimulação em consciência fonêmica e seus efeitos em relação à variável sexo. Pró-Fono. 2009; 21(1): 51-6.

10. Moura SRS, Cielo CA, Mezzomo CL. Consciência fonêmica em meninos e meninas. Rev Soc Bras Fonoaudiol. 2009; 14(2):205-11.

11. Souza APR, Pagliarin KC, Ceron MI, Deuschle VP, Keske-Soares M. Desempenho por tarefa em consciência fonológica: gênero, idade e gravidade do desvio fonológico. Rev. CEFAC. 2009; 11(ahead of print).

12. Rizzon GF, Chiechelski P, Gomes E. Relação entre consciência fonológica e desvio fonológico em crianças da 1 a série do ensino fundamental. Rev CEFAC. 2009; 11(Supl2): 201-7.

13. Rvachew S, Grawburg M. Correlates of Phonological Awareness in Preschoolers With Speech Sound Disorders. J Speech Lang Hear Res. 2006; 49(February): 74-87.

14. Marchetti PT, Mezzomo CL, Cielo CA. Desempenho em consciência silábica e fonêmica em crianças com desenvolvimento de fala normal e desviante. Rev. CEFAC. 2010;12(1): 12-20.

15. Spíndola RA, Payão LMC, Bandini HHM. Abordagem fonoaudiológica em desvios fonológicos fundamentada na hierarquia dos traços distintivos e na consciência fonológica. Rev. CEFAC. 2007; 9(2): 180-9.

16. Marchetti PT, Mezzomo CL, Cielo CA. Habilidades em consciência silábica e fonêmica de crianças com fala desviante com e sem intervenção fonoaudiológica. Rev Soc Bras Fonoaudiol. 2010;15(1):80-7.

17. Rvachew S, Chiang P, Evans N. Characteristics of Speech Errors Produced by Children With and Without Delayed Phonological Awareness Skills. Lang Speech Hear Serv Schools. 2007; 38(January): 60-71.

18. Dias RF, Mota HB, Mezzomo CL. A consciência fonológica e a consciência do próprio desvio de fala nas diferentes gravidades do desvio fonológico. Rev. CEFAC. 2009; 11(ahead of print).
19. Stoel-Gammon C. Normal and disordered phonology in two-years-olds. Top Lang Disord. 1991;11(4):21-32.

20. Brooks R, Meltzoff AN. Infant gaze following and pointing predict accelerated vocabulary growth through two years of age: a longitudinal, growth curve modeling study. J Child Lang. 2008; 35: 207-20.

21. Pedromônico MRM, Affonso LA, Sañudo A. Vocabulário expressivo de crianças entre 22 e 36 meses: estudo exploratório. Rev Bras Cresc Desenv Hum. 2002; 12(2): 13-22.

22. Hage SRV; Pereira MB. Desempenho de crianças com desenvolvimento típico de linguagem em prova de vocabulário expressivo. Rev. CEFAC. 2006; 8(4).

23. Athayde ML, Carvalho Q, Mota HB. Vocabulário expressivo de crianças com diferentes níveis de gravidade de desvio fonológico. Rev CEFAC. 2009; 11(Supl2): 161-8.

24. Rowe ML. Child-directed speech: relation to socioeconomic status, knowledge of child development and child vocabulary skill. J. Child Lang. 2008; 35: 185-205.

25. McDowel KD, Lonigan CJ, Goldstein H. Relations among socioeconomic status, age, and predictors of phonological awareness. J Speech Lang Hear Res. 2007; 50(August): 1079-92.

26. Befi-Lopes DM. Vocabulário. In: Andrade CRF, Befi-Lopes DM, Fernandes FDM, Wertzner $\mathrm{HF}$. ABFW: teste de linguagem infantil nas áreas de fonologia, vocabulário, fluência e pragmática. Barueri: Pró-Fono; 2000. cap. 2.

27. Cielo CA. Habilidades em consciência fonológica em crianças de 4 a 8 anos de idade [Tese]. Porto Alegre (RS): Doutorado em Linguística Aplicada Pontifícia Universidade Católica do Rio Grande do Sul; 2001.

28. Lazzarotto C, Cielo CA. Consciência fonológica e sua relação com a alfabetização. Rev Soc Bras Fonoaudiol. 2002; 7(2): 15-24.

29. Mota HB, Melo FMGC, Lasch SS. A consciência fonológica e o desempenho na escrita sob ditado de crianças com desvio fonológico após realização de terapia fonoaudiológica. Rev. CEFAC. 2007; 9(4): 477-82.

30. Mota HB, Kaminski TI, Nepomuceno MRF, Athayde ML. Alterações no vocabulário expressivo de crianças com desvio fonológico. Rev Soc Bras Fonoaudiol, 2009. 14(1): 41-7.

31. Befi-Lopes DM, Gandara JP. Desempenho em prova de vocabulário de crianças com diagnóstico de alteração fonológica. Rev Soc Bras Fonoaudiol. 2002;7(1):16-22. 
32. Miranda MC, Pompéia S, Bueno OFA. Um estudo comparativo das normas de um conjunto de 400 figuras entre crianças brasileiras e americanas. Rev Bras Psiquiatr. 2004; 26(4):226-33.
33. Cycowicz $Y M$, Friedman $D$, Rothstein $M$, Snodgrass JG. Picture naming by young children: norms for name agreement, familiarity, and visual complexity. J Exp Child Psychol. 1997; 65(2):171-237.

http://dx.doi.org/10.1590/S1516-18462011005000019

RECEBIDO EM: 26/03/2010

ACEITO EM: 29/10/2010

Endereço para correspondência:

Tassiana Isabel Kaminski

Rua Clemente Soltis, 067

Guarani das Missões - RS

CEP: 97950-000.

E-mails: tassikaminski@yahoo.com.br tassinha_kaminski@hotmail.com 